\title{
Field detection of material defect of dry transformer winding
}

\author{
Chao Feng ${ }^{1, *}$, Jiarui $\mathrm{Hu}^{1}$, Hongchun $\mathrm{Sun}^{2}$,Jun $\mathrm{Liu}^{3}$, Siyuan Yang ${ }^{4}$, Jun Wang ${ }^{1}$, Yi Xie ${ }^{1}$, Junjun Chen ${ }^{1}$ and Weike Liu ${ }^{1}$ \\ ${ }^{1}$ State Grid Hunan Electric Power Company Limited Research Institute, Changsha 410007, China \\ ${ }^{2}$ Hunan Xiangdian Boiler Pressure Inspection Center Co., Ltd, Changsha 410007, China \\ ${ }^{3}$ State Grid Hunan Electric Power Company Limited Yueyang Power Supply Company, Changsha 414100, China \\ ${ }^{4}$ Hunan Xiangneng Manufacture Supervision of Electrical Equipment Company Limited Research Institute, Changsha 410007, China
}

\begin{abstract}
To detect the material defect of dry transformer winding, a series of study were carried out concerning about the law of absorption ray intensity of matter, detection methods and procedures and Photographic density variation rule of copper and aluminium. The field detection was also conducted in residential area without preliminary treatment.
\end{abstract}

\section{Introduction}

The transformer can be divided into copper winding transformer and aluminium winding transformer according to different winding materials. In recent years, due to the high copper prices at home and abroad, the number of aluminium winding transformers experienced a significant growth[1-5]. At present, most of the aluminium winding transformers in the market are in the awkward situation that manufacturers swap the windings from copper wires to aluminium wires for economic benefits without the knowledge of power users[6-7]. This "aluminium-filled copper" transformer enters the power grid and brings huge security hidden trouble to the operation of the power system. At the same time, the aluminium winding transformer is sold as copper winding transformer, which also causes loss to the economic of power users.

In this paper, the field detections of material defect of dry transformer winding were carried out. The principle of the correlation detection, influence factors and detection technology were discussed.

\section{Experiment section}

The dry transformer is in service with no preprocessing was done. The $\mathrm{X}$-ray non-destructive was conducted via X-ray machine made by GE corporation. The test results are obtained by modeling and analyzing the field test data.

\section{Results and discussion}

\subsection{Law of absorption ray intensity of matter}

X-rays, like ordinary light, have a wave-particle duality, in which they interact with the atoms and electrons that make up matter, acting as particles as they illuminate it.
Because x-rays are produced by the impact of fastmoving charged particles on a metal target and have a continuous energy spectrum, $\mathrm{x}$-rays of different energies have different ability to penetrate the material under examination.

After the X-ray interact with the material, the intensity decreases. This process is not only influenced by a simple ray absorption process, but also contains many complicated physical processes. When ray transmits material, some of the rays interact with the atoms of the material to produce secondary radiation different from the energy and propagation direction of the incident beam. Therefore, absorption and attenuation are often regarded as two processes co-existing with each other.

Theoretical and experimental studies show that when narrow and single-energy $x$-rays pass through a layer of material of uniform thickness, the ray intensity declines exponentially, and the incident intensity decreases with the thickness of the penetrating object, as equation (1) to (3) shown,

$$
\begin{gathered}
\operatorname{In}\left(I_{0} / I\right)=\mu_{\mathrm{x}} \mathrm{X} \\
I=I_{0} \mathrm{e}^{-\mu_{\mathrm{x}} \mathrm{X}} \\
I_{0} / I=\mathrm{e}^{-\mu_{\mathrm{X}} \mathrm{X}}
\end{gathered}
$$

Where, the $I_{0}$ is the intensity of the incident ray beam, $I$ is the intensity of the ray beam after the transmitted material, $\mathrm{x}$ is the thickness of the material, $\mu_{\mathrm{x}}$ is the linear attenuation coefficient which represents the decay exponent of an X-ray through a substance per unit length per unit time.

In actual X-ray examination, often a broad beam ray was detected which are the combination of not only incident rays penetrating matter in a straight line without interacting with material but also those scattering rays produced in the process of interacting with matter (secondary radiation and scattering electrons). Therefore, a transmission X-ray $I_{P}$ and scattering ray $I_{X}$ reach the

\footnotetext{
* Corresponding author: 676459812@qq.com
} 
detector at the same time, the strength of total X-ray intensity was set as $I$, as shown in equation (4),

$$
I=(1+\mathrm{n}) I_{0} \cdot \mathrm{e}^{-\mu_{\rho \mathrm{x}}}
$$

Where, the $\rho$ is the density of matter. And in industrial X-ray testing, the X-ray used cannot be monochromatic ray but polychromatic ray that obtained by bremsstrahlung with continuously varying wavelengths. When the polychromatic ray penetrates the object, the attenuation coefficient $\mathrm{z}$ is no longer constant, but decreases as the energy of the photon increases, and becomes constant $\mu(E)$, as illustrated in equation (5),

$$
I(x)=\int_{0}^{\mathrm{E}_{\max }}(1+\mathrm{n}) I_{0}(\mathrm{E}) \cdot \mathrm{e}^{-\mu \mathrm{E}(\mathrm{x})} d E
$$

Where, $\mu \mathrm{E}(\mathrm{x})$ is the attenuation coefficient of the photon with energy $\mathrm{E}$ in the polychromatic ray, $I_{0}(\mathrm{E})$ is the incident intensity of the photon with energy $E$ in the polychromatic ray, and $I(\mathrm{x})$ is the transmission intensity when the polychromatic ray penetrates the substance with the thickness of $\mathrm{x}$.

\subsection{Detection methods and procedures}

The detection process layout is shown in Fig.1. The copper and aluminium multi-steps samples are placed directly in front of the focus of the X-ray machine. The $\mathrm{X}$-ray radiography in the laboratory was made of MCD4 $\mathrm{X}$-ray film, the front and rear Intensifying screens were all $\mathrm{Pb}$ lead foils with the thickness of $0.15 \mathrm{~mm}$. The Xray radiography process focal length $F$ was $700 \mathrm{~mm}$, the tube voltage was $150 \mathrm{kV}$, and the exposure was $20 \mathrm{~mA} / \mathrm{min}$. The corresponding relationship of X-ray radiography process parameters and serial numbers was shown in Table 1 . The exposure time was $60 \mathrm{~s}$.

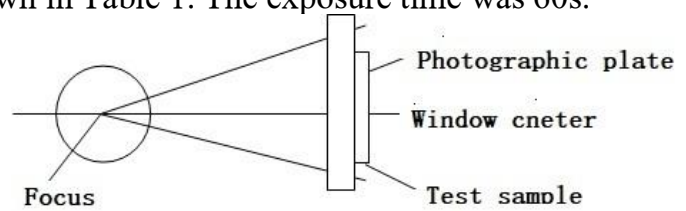

Fig. 1. Detection process layout.

Table 1. X - ray radiography process parameters.

\begin{tabular}{|c|c|c|}
\hline Serial number & A & B \\
\hline Focal length/mm & 500 & 500 \\
\hline Tube voltage/kV & 150 & 250 \\
\hline Tube current/mA & 20 & 20 \\
\hline Film type & $\mathrm{D} 4$ & $\mathrm{D} 4$ \\
\hline Intensifying screen & $0.15 \mathrm{~mm} \mathrm{~Pb}$ & $0.15 \mathrm{~mm} \mathrm{~Pb}$ \\
\hline
\end{tabular}

Process A and process B were used to conduct X-ray detection on the pure copper and aluminium winding $\mathrm{c}$ test sample with thickness ranging from 10 to $50 \mathrm{~mm}$. After the darkroom disposal with the development time of 70 s and fixing time of $300 \mathrm{~s}, 5$ simulated aluminium winding test samples with thickness in the range of 10 to $50 \mathrm{~mm}$ were obtained.

\subsection{Photographic density variation rule of copper and aluminium}

Nigrometer was used to measure the photographic density of the radiograph of copper and aluminium winding simulated multi-steps samples, and the logarithm of the photographic density was taken, as shown in Table 2 and Table 3.

Table 2. Logarithm of the photographic density of radiograph of copper samples.

\begin{tabular}{|c|c|c|}
\hline Thickness(H) & Serial A(ln D) & Serial B(ln D) \\
\hline $10 \mathrm{~mm}$ & 1.022451 & $/$ \\
\hline $20 \mathrm{~mm}$ & -0.03046 & 0.982078 \\
\hline $30 \mathrm{~mm}$ & -0.79851 & -0.01005 \\
\hline $40 \mathrm{~mm}$ & -1.56065 & -0.96758 \\
\hline $50 \mathrm{~mm}$ & -2.60795 & -1.83258 \\
\hline
\end{tabular}

Table 3. Logarithm of the photographic density of radiograph of aluminium sample.

\begin{tabular}{|c|c|c|}
\hline Thickness(H) & Serial A(ln D) & Serial B(ln D) \\
\hline $10 \mathrm{~mm}$ & $/$ & $/$ \\
\hline $20 \mathrm{~mm}$ & 1.255616 & 1.313724 \\
\hline $30 \mathrm{~mm}$ & 1.018847 & 0.940007 \\
\hline $40 \mathrm{~mm}$ & 0.71784 & 0.667829 \\
\hline $50 \mathrm{~mm}$ & 0.270027 & \\
\hline
\end{tabular}

The $\operatorname{lnD}-\mathrm{H}$ function curves of copper and aluminium was fitted as shown in Fig.2. The four curves in the figure are all close to straight lines in which the slope of copper is about -0.086 and that of aluminium is about 0.03285 .

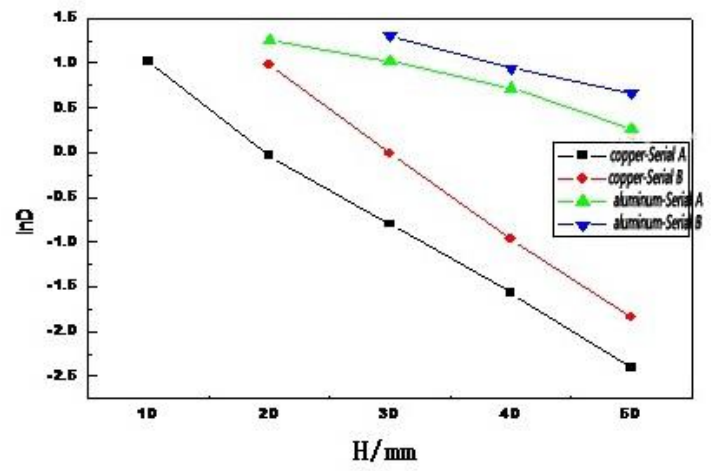

Fig. 2. $\ln \mathrm{D}-\mathrm{H}$ function curves of copper and aluminium.

According to the test statistics, the logarithmic slope difference of blackness between copper winding and aluminium winding is relatively small under different 
voltages. It indicates that it is feasible to identify materials by the different absorption characteristics of copper and aluminium to $\mathrm{X}$-ray.

\subsection{Field detection of dry transformer windings}

The field detection was carried out in some residential areas because the operation and maintenance personnel think that there are material defects in the dry transformer windings. The field test layout is shown in Fig. 3 ana Fig.4.

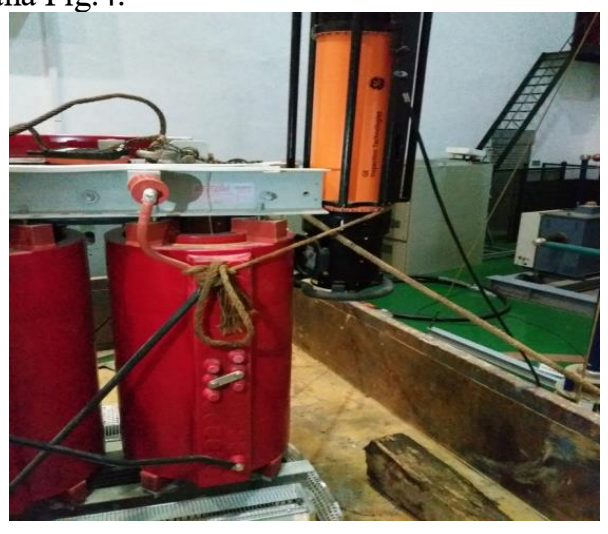

Fig. 3. Field test layout of dry transformer winding.

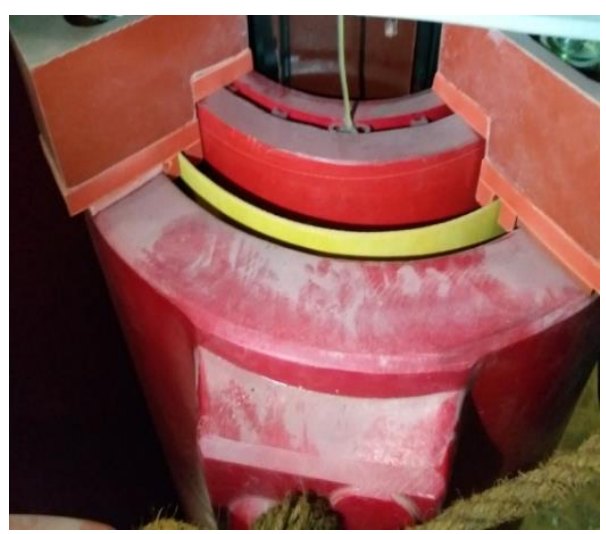

Fig. 4. Partial enlarged drawing of inspection area.

\subsubsection{1\# 2000kVA dry transformer}

The measured thickness of the outer layer winding of the dry type transformer is $60 \mathrm{~mm}$. The thickness of the resin layer of the thin insulated dry type transformer is about $4-5 \mathrm{~mm}$, the thickness of the inter-turn insulation layer is about $2 \mathrm{~mm}$, and the thickness of the copper or aluminium layer after removing the insulation layer is $53 \mathrm{~mm}$. The outer layer winding of \#1 dry transformer A phase was tested. When the dosimeter was saturated, the saturation voltage of the X-ray meter was $155 \mathrm{kV}$ as shown in Fig.5.

The top curve in Fig. 5 is the theoretical curve of copper material, and the bottom curve is the theoretical curve of aluminium material. The field detection result of 1 \# 2000kVA dry transformer was also labelled in the picture. Based on the different $\mathrm{x}$-ray absorption rate of copper and aluminium, there is a distinct gap between the saturated voltage of their theoretical curves. In the first case, if the acquired data is above the theoretical curve of copper material, it indicated that the examined dry transformer was wrapped by copper winding. And in the second case, if the acquired data is between the theoretical curve of copper material and aluminium material, it means the dry transformer winding was composed of the mixture of copper material and aluminium material. In this case, it is the third case that the acquired data was below the theoretical curve of aluminium material which directly indicating that the dry transformer winding was manufactured by undesirable aluminium material.

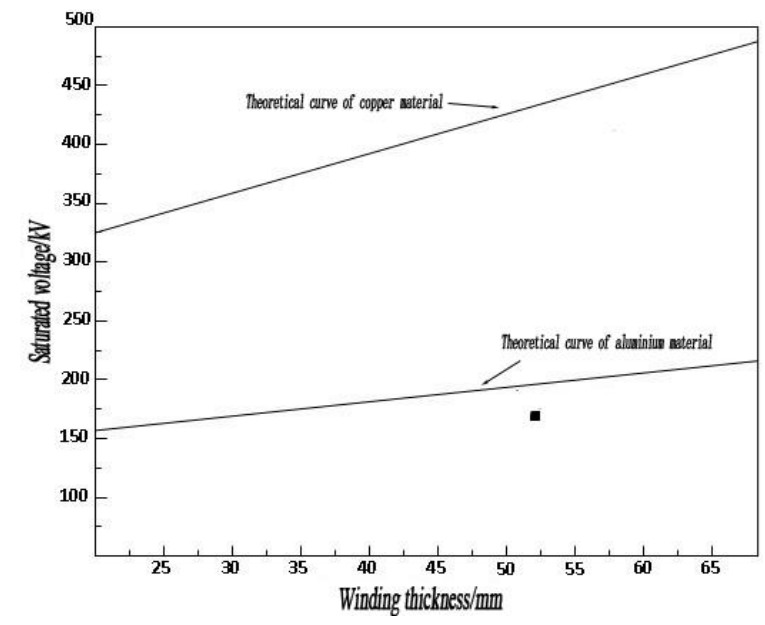

Fig. 5. Acquired data of saturated voltage of $1 \#$ sample.

\subsubsection{2\# 800kVA dry transformer}

The measured thickness of the outer layer winding of the dry type transformer is $50 \mathrm{~mm}$. The thickness of the resin layer of the thin insulated dry type transformer is about $4-5 \mathrm{~mm}$, the thickness of the inter-turn insulation layer is about $2 \mathrm{~mm}$, and the thickness of the copper or aluminium layer after removing the insulation layer is $43 \mathrm{~mm}$. The outer layer winding of \#2 dry transformer A phase was tested. When the dosimeter was saturated, the saturation voltage of the X-ray meter was $410 \mathrm{kV}$ as shown in Fig.6.

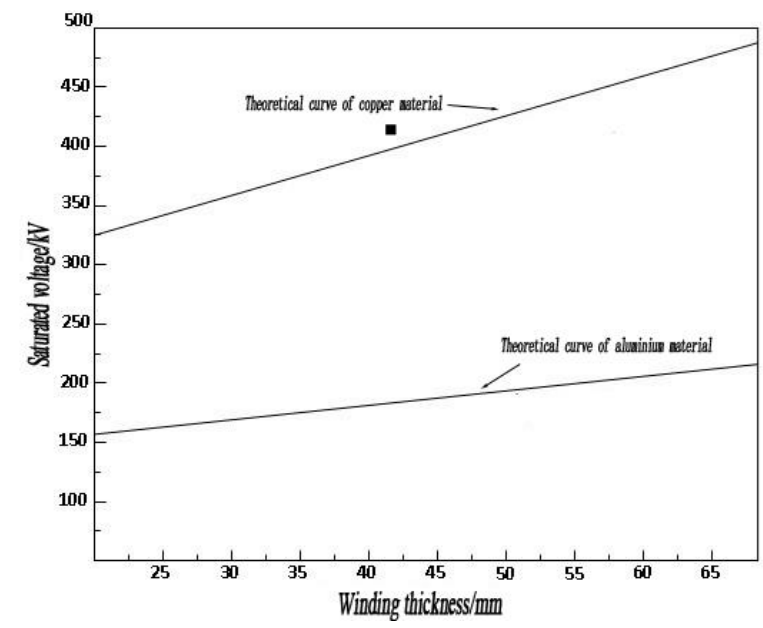

Fig. 6. Acquired data of saturated voltage of 2\# sample.

Based on the above discussion and analysis, the The field detection result of $2 \# 800 \mathrm{kVA}$ dry transformer was 
also labelled in the Fig.6. It is obvious that the acquired data is above the theoretical curve of copper material which indicating that the winding of $2 \# 800 \mathrm{kVA}$ dry transformer is copper material.

\subsubsection{The impact of aluminium winding}

Aluminium material has the advantages of low cost and easy machining in manufacturing dry-type transformer windings. The impact insulation and dynamic stability of aluminium winding transformers with reasonable design and reliable process are comparable to those of copper winding transformers. However, the power frequency insulation, thermal stability, winding stability, oxidation resistance, softness, partial discharge performance is inferior to copper winding transformer in most situations.

A large number of examples show that the aluminium winding dry transformers usually work well under low load and less external impact, but the effective service life is comparatively shorter than copper winding dry transformers. However, when the load exceeds $50 \%$ of the rated capacity for a long time and the external impact is large, the service life of the aluminium winding dry transformer will be greatly shortened, accompanied by abnormal noise and unexpected failure in the process of work.

\section{Conclusion}

1) The material detection method of dry transformer winding based on X-ray absorption principle and related theoretical basis are introduced in detail. This method can be used to detect the material of dry transformer winding in actual field test, and realize accurate judgment of copper and aluminium.

2) The materials of tested dry transformer winding with the rated capacity of $2000 \mathrm{kVA}$ and $800 \mathrm{kVA}$ were copper and aluminium according to the field detection results. Material detection should be strengthened, as the power frequency insulation, thermal stability, winding stability, oxidation resistance, softness, partial discharge performance of dry transformer with aluminium winding could not meet the requirements of harsh working conditions.

\section{References}

1. S.W.Liu, J.L.Yi, Transformer 56, 3(2019).

2. W.M.Lu, Z.Y.Du, Y.Li, W.C.Li, C.Peng, Guangdong Electric Power 31, 10(2018).

3. J.H.Liu, S.Hu, X.W.Wu, J.W.Peng, L.Lu, Hunan Electric Power 37, 2(2019).

4. T.N.Li, Q.Ma, J.P.Gui, Electric Eng. 9, 1(2019).

5. B.Ji, J.Tao, H.B.Zhong, Electric Eng. 23, 1(2019).

6. D.G.Cai, J.Q.Tang, Insulating Mater. 52, 11(2019).

7. Y.Zhang, X.H.Yang, K.Q.Zhao, Electrotech. Electric 12, 1(2019). 